\title{
Influence of sieving time on the efficiency and accuracy of grain-size analysis of beach and dune sands
}

\author{
JORGE ROM ÁN-SIERRA, JUAN J. MUÑOZ-PEREZ and MARINA NAVARRO-PONS \\ Applied Physics Department, Sea Sciences Faculty, University of Cadiz, 11510 - Puerto Real (Cadiz), \\ Spain (E-mail: jorge.roman@uca.es)
}

Associate Editor - Nick Lancaster

\begin{abstract}
Grain size is a fundamental property of sediments and is commonly used to describe sedimentary facies and classify sedimentary environments. Among the various conventional techniques utilized to determine grain-size frequency distributions, sieving is the most widely applied procedure. The accuracy of such analyses is, among other factors, strongly dependent on the sieving time. However, despite a substantial amount of research in this field, optimal sieving times for different types of sediments have, to date, not been established. In this article, the influence of sieving time on grain-size analyses of medium-grained microtidal and mesotidal beach and dune sands has been determined. To assess the precision of important textural parameters, such as median grain size, sorting, skewness and kurtosis, an error analysis was carried out for different sieving times $(2,5,10,15$ and 20 minutes). After calibrating the analytical and sampling methodologies, significant deviations were registered when sieving time was less than 10 minutes. However, such deviations were very small and grain-size distributions remained almost identical for sieving times of 10 minutes and longer, relative errors being as low as $0 \%$ in some cases.
\end{abstract}

Keywords Grain size, granulometric analysis, kurtosis, median grain diameter, sieving time, skewness, sorting.

\section{INTRODUCTION}

Grain size is one of the most fundamental properties of sediments and is of primary importance for the entrainment, transport and deposition of granular material. In this context, grain-size distributions provide important clues to sediment provenance, transport history and depositional conditions (e.g. Folk \& Ward, 1957; Friedman, 1979; Bui et al., 1990; Bernabeu et al., 2002; Gutiérrez-Mas et al., 2003; Benavente et al., 2005; Gómez-Pina et al., 2006; Baquerizo \& Losada, 2008) and grain-size analysis is an essential tool for classifying sedimentary facies and environments (Folk, 1954; Shepard, 1954; Blair \& McPherson, 1999; Flemming, 2000; Anfuso \& Gracia, 2005; Román-Sierra et al., 2011). Currently, techniques commonly employed in grain-size determination include direct measurement, dry and wet sieving, sedimentation, or the use of different particle-size analysers, including laser granulometers, X-ray-based Sedigraphs and Coulter particle counters (Blott \& Pye, 2001, 2006), or the autocorrelation technique for estimating grain size from digital images of sand beds (Rubin, 2004; Buscombe \& Masselink, 2009). In the case of sand and gravel, the most common technique used for textural studies is sieving, a method with a very long tradition in sedimentology (Blatt et al., 1980).

More reviews of conventional techniques used in modern geological particle-size analysis can be found in Syvitski (1991), Barbanti \& Bothner (1993) and Beuselinck et al. (1998). Mathematical treatments of granulometry, originally proposed by Matheron (1975) to 
characterize sieving processes in random sets, are used for grain-size and textural classifications because they are based on comprehensive statistical analyses of grain-size frequency distributions (Chen \& Dougherty, 1994). Sediments are frequently classified according to their sand/ silt/clay ratios (e.g. Folk, 1954, 1974; Shepard, 1954; Flemming, 2000) or gravel/sand/mud ratios (e.g. Folk, 1954, 1974; Blair \& McPherson, 1999). Moreover, the internationally most commonly used grade scale (Tanner, 1969; Friedman \& Sanders, 1978) is based on the logarithmic transformation of the millimetre-scale (Wentworth, 1922) which was subsequently expressed mathematically by Krumbein (1934a) in terms of the binary logarithms of the millimetre-scale, thereby giving birth to the so-called 'phi-scale'. It facilitated a more rigorous statistical analysis of grain-size frequency distributions (Krumbein, 1939). The mathematical expression of the phiscale $(\phi)$ is given by:

$$
\mathrm{D}(\varphi)=-\log _{2} \mathrm{~d}(\mathrm{~mm})
$$

and, conversely:

$$
\mathrm{d}(\mathrm{mm})=2^{-\mathrm{D}(\varphi)}
$$

where $\mathrm{D}$ is the grain diameter in phi units, and $\mathrm{d}$ is the grain diameter in millimetres.

In the case of large sample sets, the computation of statistical parameters from grain-size frequency distributions can be a laborious procedure and depends on the methodology used. According to Blott \& Pye (2001), the parameters used to describe a grain-size distribution fall into four principal groups: average size, sorting, skewness and kurtosis. These parameters can be determined arithmetically or geometrically (in metric units) and logarithmically (in phi units) by extraction of relevant percentile values from graphic plots (Folk \& Ward, 1957), or by the mathematical method of moments using the largest possible number of evenly spread percentile values that can feasibly be extracted from a distribution (Krumbein \& Pettijohn, 1938; Folk, 1974; Friedman \& Johnson, 1982; USACE, 2008). These methods are also frequently used as effective descriptors of texture and grain shape (Batman \& Dougherty, 1997; Sand \& Dougherty, 1998). The analysis using textural characteristics, such as mean or median grain size, sorting, skewness and kurtosis, to distinguish between different sedimentary environments must be examined more critically because the parameters strongly depend on the method used to obtain these values (Syvitski, 1991). In this sense, only frequency curves generated by the same method, and subsequently processed by identical computational procedures, can be meaningfully compared (Flemming, 2007). Furthermore, results obtained using different methods may not be directly comparable, and it can be difficult to assimilate size data obtained using more than one method (Pye, 1994). It is also extremely difficult to specify the accuracy of the measures when the particles are of irregular shape, as in the case of bioclastic sediments. Precision, i.e. the reproducibility of results, may be determined through the systematic analysis of several splits of a sample, several analyses of the same sample or the analysis of several samples collected at the same locality. According to Syvitski (1991), it is important that precision be reported because sieving time can influence the results.

Several studies have been carried out to evaluate sifting efficiency in relation to sieving time. The principal hypothesis was that longer sieving times were needed when fine material was present because the finer the material, the greater the number of sieves that had to be passed, and because the time taken for grains to pass through a sieve increased for smaller apertures (Mizutani, 1963). On the basis of such considerations, a median sieving time of 20 min was proposed by Syvitski (1991) and Lund-Hansen \& Oehmig (1992), or 15 min by US Army Corps of Engineers (USACE), 2008. In summary, the minimum sieving times recommended in the literature show considerable variation and, therefore, can be regarded as very general guidelines only. In particular, systematic investigations on optimal sediment-specific and environment-specific sieving efficiency are currently still lacking.

This study was undertaken with the purpose of optimizing sieving time in the analysis of coastal dune and beach sediments, the main aim being to establish the minimum time required to obtain accurate results for medium-grained beach and dune sands. In addition, relative errors for different sieving times were investigated. This study thus attempts to provide an optimal sieving time, assuming a negligible error linked to both sampling and sieving methodologies.

\section{STUDY AREA}

Ten samples were collected from both beach and dune environments of the littoral zone near the cities of Cadiz and Tarifa, south-western Spain (Fig. 1). The beach samples were col- 
lected at Victoria beach (Cadiz) and Valdevaqueros beach (Tarifa), the dune samples on the highly mobile transverse dune system at Valdevaqueros, which has one of the highest aeolian sand transport capacities in Europe (MuñozPerez et al., 2009; Navarro et al., 2011).

The beach samples were collected from the uppermost $20 \mathrm{~cm}$ of the dry, the intertidal and the submerged beach. The maximum tidal range at Victoria beach is $3.8 \mathrm{~m}$ (Muñoz-Perez \& Med-

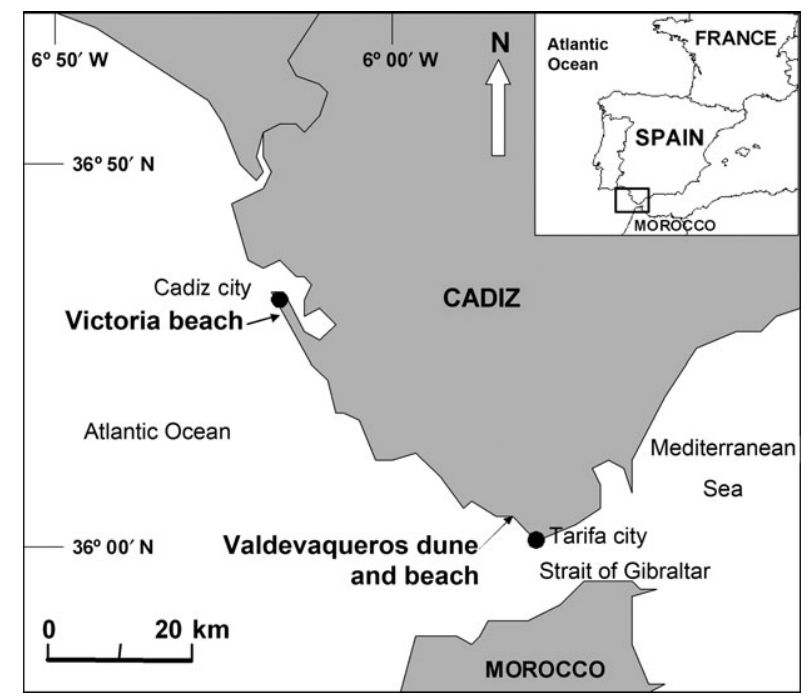

Fig. 1. Location of the Valdevaqueros dune and beach, and Victoria beach study areas. ina, 2000) and that at Valdevaqueros is $1.5 \mathrm{~m}$; the beaches are thus, respectively, mesotidal and microtidal according to the classification of Davies (1964). The yearly mean wave height in both areas is estimated to be between $0.5 \mathrm{~m}$ and $1.0 \mathrm{~m}$, respectively (Spanish Port System, 2011). The dune sediments at Valdevaqueros were collected from the leeward face, dune crest, windward face and the dune foot (Fig. 2).

\section{METHODOLOGY}

\section{Sieving analysis and statistical computations}

Several techniques are available to analyse the size of beach materials, each covering a restricted range in grain size. In the size range from medium gravels, through sand to coarse silt, grain-size analysis is usually carried out using certified sieves. In the present case, sampling and sieving procedures follow the recommendations proposed in Syvitski (1991) and in the laboratory procedures of USACE (2008). Table 1 lists the nine sieve intervals between $2 \mathrm{~mm}$ and $0.063 \mathrm{~mm}$ chosen for this experiment.

Each sand sample weighed around $100 \mathrm{~g}$. The samples were analysed using sieving times of 2 , 5, 10, 15 and 20 min in a Ro-Tap sieve shaker machine (W.S. Tyler Industrial Group, Mentor,

A

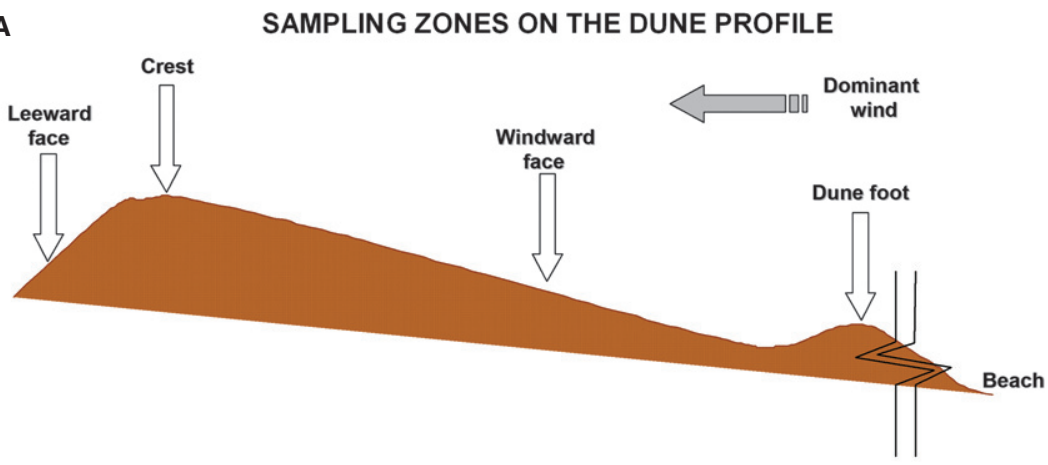

B

SAMPLING ZONES ON THE BEACH PROFILES

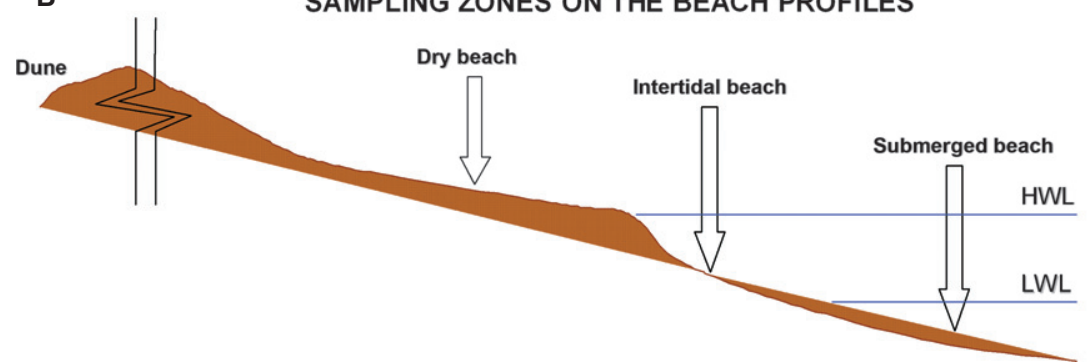

Fig. 2. Sampling locations along Valdevaqueros dune (A) and Victoria and Valdevaqueros beach (B) profiles: 'HWL' - Highest Water Level; 'LWL' - Lowest Water Level. 
Table 1. Sand sieves chosen (nine) - Several classifications of sediment particle sizes.

\begin{tabular}{llrl}
\hline $\begin{array}{l}\text { Wentworth } \\
\text { classification }\end{array}$ & $\begin{array}{l}\text { Size in } \\
\text { mm }\end{array}$ & Phi size & $\begin{array}{l}\text { US standard } \\
\text { sieve }\end{array}$ \\
\hline Gravel & $>2.000$ & $<-1.000$ & $<10$ \\
Very coarse & 2.000 to 1.000 & 0.000 & 10 to 40 \\
sand & & & \\
Coarse sand & 1.000 to 0.710 & 0.500 & \\
& 0.710 to 0.500 & 1.000 & \\
Medium sand & 0.500 to 0.355 & 1.500 & 40 to 200 \\
& 0.355 to 0.250 & 2.000 & \\
Fine sand & 0.250 to 0.125 & 3.000 & \\
Very fine & 0.125 to 0.063 & 4.000 & \\
sand & & & \\
Silt and clay & $<0.063$ & $>4.000$ & $>230$ \\
\hline
\end{tabular}

$\mathrm{OH}$, USA) operated at $2.6 \mathrm{rpm}$ and 300 taps/ min. The individual sieve fractions were subsequently weighed with a $\pm 0.01 \mathrm{~g}$ precision balance. After each analysis, the sieve weight, the retained percentage, the percentage passing, the analysis liability, the granulometric curve and the histogram with the line tendency for each sieve were computed.

Natural sediment samples are commonly composed of variously shaped particles covering a variable range of grain sizes. It is thus necessary to characterize each sample by means of a typical grain diameter as a measure of the central tendency of the distribution. Besides the mean diameter, the median grain diameter $\left(D_{50}\right)$ is frequently chosen for this purpose (USACE, 2008). The $D_{50}$ value represents the 50th percentile of a grain-size frequency distribution and is therefore the point at which, by weight, half of the particles in the sample have a larger diameter and half have a smaller diameter. In addition, other percentiles required for statistical analyses have also been determined. For example, $\mathrm{D}_{84}$ is the 84th percentile and hence the diameter at which $84 \%$ of the sediment, by weight, has a smaller diameter. An equivalent definition holds for the median of the phi-size distribution $\phi_{50}$ or for any other percentiles of the phi-scale $\left(\phi_{05}, \phi_{16}, \phi_{25}\right.$, $\phi_{50}, \phi_{75}, \phi_{84}$ and $\left.\phi_{95}\right)$. Additional parameters, i.e. sorting, skewness and kurtosis, are used to indicate how a size distribution deviates from a log-normal distribution. The corresponding equations can be found in Folk \& Ward (1957),
Folk (1974) and Blott \& Pye (2001). These textural parameters are the ones most commonly used to characterize a sediment sample and are widely applied in describing the sediment of depositional environments, including beaches and dunes. Verbal expressions for different categories of standard deviation (sorting), skewness and kurtosis are listed in Table 2.

\section{Computation of relative errors in relation to sieving time}

Relative errors were calculated for each of the studied parameters, considering all samples and sieving times. The relative error was defined as the absolute error divided by the theoretically most exact value that corresponds to a 20 min sieving time. By using this procedure, the error for each time interval was calculated. To obtain relative errors pertaining to the median diameter $\left(D_{50}\right)$, a representative master sample was generated in each case (Medina et al., 1994; Galofré et al., 1996). For this purpose, several related samples from a depositional environment were blended into a single master sample for which the grainsize distribution and the textural parameters were then determined. In this study, representative master distributions were generated for the dune and the two beach environments.

\section{Methodological accuracy}

In the present context, the accuracy of an analysis is dependent on the average grain size of a sample, whereas the precision of an analysis, i.e. the reproducibility of the results, may be determined by comparing the results derived either from the separate analysis of several splits of a sample, or by reanalysing the same sample several times (Syvitski, 1991). In the experiments described here, errors associated with the sieving process were assessed by sieving the same sand sample three times. By using this procedure, the variability associated with sieving was determined. In addition, the error associated with sampling was assessed by comparing the results obtained from three samples collected at the same site.

\section{RESULTS}

\section{Precision of the method}

Although the initial weight of the sieved samples was higher than the minimum recom- 
Table 2. Qualitative sediment distribution ranges for standard deviation, skewness and kurtosis (adapted from USACE, 2008).

\begin{tabular}{|c|c|c|}
\hline Phi range & Parameter & \\
\hline & Standard deviation (sorting) & \\
\hline$<0.35$ & Very well-sorted & \\
\hline $0.35-0.50$ & Well-sorted & \\
\hline $0.50-0.71$ & Moderately well-sorted & \\
\hline $0.71-1.00$ & Moderately sorted & \\
\hline $1.00-2.00$ & Poorly sorted & \\
\hline $2.00-4.00$ & Very poorly sorted & \\
\hline$>4.00$ & Extremely poorly sorted & \multirow{6}{*}{ Coarse-skewed } \\
\hline & Coefficient of skewness & \\
\hline$<-0.3$ & Very coarse-skewed & \\
\hline-0.3 to -0.1 & Coarse-skewed & \\
\hline-0.1 to +0.1 & Near-symmetrical & \\
\hline+0.1 to 0.3 & Fine-skewed & \\
\hline \multirow[t]{2}{*}{$>+0.3$} & Very fine-skewed & \multirow{8}{*}{ Mesokurtic } \\
\hline & Coefficient of kurtosis & \\
\hline$<0.65$ & Very platykurtic (flat) & \\
\hline $0.65-0.90$ & Platykurtic & \\
\hline $0.90-1.11$ & Mesokurtic (normal peakedness) & \\
\hline $1.11-1.50$ & Leptokurtic (peaked) & \\
\hline $1.50-3.00$ & Very Leptokurtic & \\
\hline$>3.00$ & Extremely leptokurtic & \\
\hline
\end{tabular}

mended in the literature (for example, $40 \mathrm{~g} / \mathrm{sam}-$ ple in USACE, 2008), it was limited to $100 \mathrm{~g} /$ sample to minimize the errors of precision. In the present case, the precision of the method can be estimated as a function of sampling and sieving analysis.

\section{Computational precision related to sand sampling}

To estimate the error introduced when collecting the sample in the field, several samples were taken at the same locality. For this purpose, an 
intertidal locality along the Victoria beach profile was selected because it consisted of moderately well-sorted sand $\left(\sigma_{\phi}=0 \cdot 60\right)$, and because sampling was both easier and less costly than in the submerged zone. The samples were analysed following the methodology outlined above.

The results, which are listed in Table 3, show a similar retained percentage for each of the sieves. The standard deviation calculated for each sample indicates irrelevant differences and low maximum relative errors. For the sieve fractions close to the $D_{50}$ value, maximum relative errors are almost zero. Consistent with corresponding published data, the probable sampling error is reduced by about $30 \%$ when two samples, by $50 \%$ when four samples, by $60 \%$ when six samples were combined, respectively. The gain in error reduction thus decreases as the sample number increases, 10 samples merely achieving a 70\% error reduction (Krumbein, 1934b; Krumbein \& Pettijohn, 1938).

\section{Precision of the sieving analysis}

To determine the accuracy and precision of the applied methodology, the same sand sample was analysed three times for a sieving period of 5 min. The material loss commonly associated with sieving has been discussed in Dalsgaard \& Jensen (1985), where an average loss per analysis of $0.02 \%$ was established for a $30 \mathrm{~g}$ sample. This forfeiture can be considered negligible because it does not represent a significant proportion of the total sample. In the case of the intertidal sample from Victoria beach (Table 4), a maximum loss per sieving analysis of $0.01 \%$ for a $100 \mathrm{~g}$ sample was registered. Thus, losses during the analysis were negligible.

The methodological error is expressed as the standard deviation of the retained sample for each sieve. In the present case, the standard deviation is nearly zero for all sieves, showing a $<5.4 \%$ maximum relative error. From this, it can be concluded that the methodological error associated with sampling and analysis can be considered negligible. This fact increases the confidence in the results of the various sieving times chosen in this study.

After the precision computations, the main parameters (median size, sorting, skewness and kurtosis) obtained for different sieving times (2, 5, 10, 15 and $20 \mathrm{~min})$ were compared for all

Table 3. Analyses results obtained from three samples at the same location in Victoria beach.

\begin{tabular}{|c|c|c|c|c|c|c|}
\hline $\begin{array}{l}\text { Sieve } \\
\text { size (mm) }\end{array}$ & $\begin{array}{l}1 \text { st analysis } \\
\% \text { retained }\end{array}$ & $\begin{array}{l}\text { 2nd analysis } \\
\% \text { retained }\end{array}$ & $\begin{array}{l}\text { 3rd analysis } \\
\% \text { retained }\end{array}$ & Average & $\begin{array}{l}\text { Standard } \\
\text { deviation }\end{array}$ & $\begin{array}{l}\text { Maximum } \\
\text { relative error (\%) }\end{array}$ \\
\hline $2 \cdot 000$ & $1 \cdot 14$ & $1 \cdot 10$ & $1 \cdot 23$ & $1 \cdot 16$ & $0 \cdot 07$ & $6 \cdot 34$ \\
\hline $1 \cdot 000$ & $1 \cdot 01$ & 0.96 & 0.93 & 0.97 & $0 \cdot 04$ & $3 \cdot 79$ \\
\hline $0 \cdot 710$ & 0.98 & 0.99 & 0.79 & 0.92 & $0 \cdot 11$ & $14 \cdot 13$ \\
\hline $0 \cdot 500$ & $2 \cdot 92$ & $2 \cdot 90$ & $2 \cdot 59$ & $2 \cdot 80$ & $0 \cdot 19$ & $7 \cdot 61$ \\
\hline $0 \cdot 350$ & $12 \cdot 14$ & $12 \cdot 09$ & $12 \cdot 20$ & $12 \cdot 14$ & $0 \cdot 06$ & 0.47 \\
\hline $0 \cdot 250$ & $37 \cdot 27$ & $37 \cdot 22$ & $37 \cdot 36$ & $37 \cdot 28$ & $0 \cdot 07$ & $0 \cdot 21$ \\
\hline $0 \cdot 125$ & $41 \cdot 36$ & $41 \cdot 50$ & $41 \cdot 59$ & $41 \cdot 48$ & $0 \cdot 12$ & $0 \cdot 30$ \\
\hline 0.063 & $2 \cdot 83$ & $2 \cdot 91$ & $2 \cdot 91$ & $2 \cdot 88$ & 0.05 & $1 \cdot 85$ \\
\hline 0.000 & 0.33 & $0 \cdot 31$ & $0 \cdot 38$ & $0 \cdot 34$ & 0.04 & $11 \cdot 76$ \\
\hline
\end{tabular}

Table 4. Results obtained from three analyses on the same intertidal sample from Victoria beach.

\begin{tabular}{|c|c|c|c|c|c|c|}
\hline Sieve size (mm) & $\begin{array}{l}1 \text { st analysis } \\
\% \text { retained }\end{array}$ & $\begin{array}{l}2 \text { nd analysis } \\
\% \text { retained }\end{array}$ & $\begin{array}{l}\text { 3rd analysis } \\
\% \text { retained }\end{array}$ & Average & $\begin{array}{l}\text { Standard } \\
\text { deviation }\end{array}$ & $\begin{array}{l}\text { Maximum } \\
\text { relative error (\%) }\end{array}$ \\
\hline $2 \cdot 000$ & $0 \cdot 10$ & $0 \cdot 10$ & $0 \cdot 11$ & $0 \cdot 10$ & 0.00 & $4 \cdot 08$ \\
\hline $1 \cdot 000$ & 0.46 & 0.46 & 0.45 & 0.46 & $0 \cdot 00$ & 0.90 \\
\hline $0 \cdot 710$ & $1 \cdot 14$ & $1 \cdot 09$ & $1 \cdot 09$ & $1 \cdot 11$ & 0.03 & $2 \cdot 62$ \\
\hline $0 \cdot 500$ & $4 \cdot 46$ & $4 \cdot 47$ & $4 \cdot 44$ & $4 \cdot 45$ & 0.02 & $0 \cdot 33$ \\
\hline $0 \cdot 350$ & $13 \cdot 34$ & $13 \cdot 35$ & $13 \cdot 35$ & $13 \cdot 34$ & 0.00 & $0 \cdot 02$ \\
\hline $0 \cdot 250$ & $39 \cdot 33$ & $39 \cdot 60$ & $39 \cdot 86$ & $39 \cdot 60$ & $0 \cdot 27$ & $0 \cdot 67$ \\
\hline $0 \cdot 125$ & $39 \cdot 56$ & $39 \cdot 36$ & $39 \cdot 22$ & $39 \cdot 38$ & $0 \cdot 17$ & $0 \cdot 45$ \\
\hline $0 \cdot 063$ & $1 \cdot 57$ & $1 \cdot 51$ & 1.42 & $1 \cdot 50$ & 0.08 & $5 \cdot 37$ \\
\hline $0 \cdot 000$ & 0.06 & 0.06 & 0.06 & 0.06 & 0.00 & $0 \cdot 00$ \\
\hline
\end{tabular}

(C) 2013 The Authors. Journal compilation (C) 2013 International Association of Sedimentologists, Sedimentology, 60, 1484-1497 
samples from each environment to establish the optimal sieving time in relation to the highest precision. The relative errors corresponding to each parameter at different times were also established. By using this procedure, the influence of sieving time was determined for the 10 samples collected in the three different environments.

\section{Influence of sieving time on Victoria beach samples}

The granulometric analyses of the three sand samples collected along the transverse profile across Victoria beach show that the sediment consists of medium sand with $\mathrm{D}_{50}$-values ranging from 0.28 to $0.32 \mathrm{~mm}$ after the $2 \mathrm{~min}$ sieving time (Fig. 3). In each case, there is a clearly decreasing tendency with increasing sieving time, the values stabilizing after $10 \mathrm{~min}$. With respect to the master sample from Victoria beach, the relative error in the $\mathrm{D}_{50}$-value always remains $<10 \%$, reaching a value $<3 \%$ after 10 min sieving time. Sorting shows a slight decreasing tendency over the first $10 \mathrm{~min}$ of sieving time and then becomes stable. The sediment is moderately well-sorted $\left(\sigma_{\phi}=0.59\right.$ to 0.71$)$, the relative error initially being $<8 \%$, reaching $0 \%$ after $10 \mathrm{~min}$.
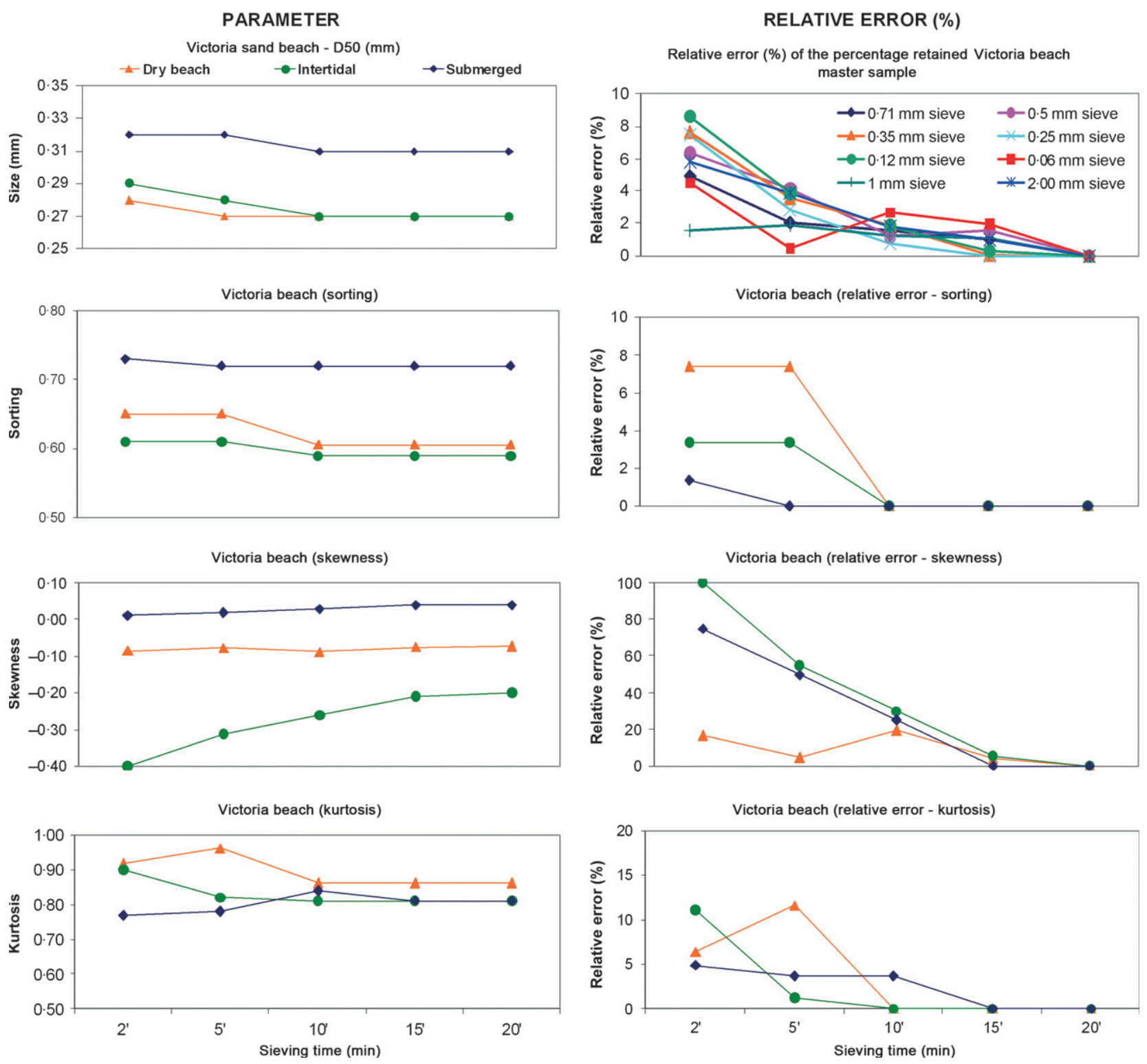

Fig. 3. Median grain size, sorting, skewness, kurtosis and relative errors as a function of sieving time for Victoria beach samples. 
Skewness, in turn, changes negligibly for both the submerged and dry beaches, the distribution essentially remaining symmetrical. In the case of the intertidal sample, by contrast, the skewness decreases progressively from an initial negative value $\left(\alpha_{\phi}=-0.40\right)$ after 2 min sieving time to a less negative value $\left(\alpha_{\phi}=-0 \cdot 20\right)$ after $20 \mathrm{~min}$ sieving time, the median diameter becoming slightly finer from 0.29 to $0.27 \mathrm{~mm}$. The relative error is $100 \%$ for $2 \mathrm{~min}, 30 \%$ for $10 \mathrm{~min}$ and $<10 \%$ from 15 min onward.

The kurtosis values of all three samples converge towards the $10 \mathrm{~min}$ sieving time and remain stable thereafter. All samples show a platykurtic distribution throughout $\left(\beta_{\phi}=0.80\right.$ to
0.90), and the relative errors decrease from initially 5 to $12 \%$ to $<4 \%$ after $10 \mathrm{~min}$.

\section{Influence of sieving time in the Valdevaqueros beach samples}

The sediment of the microtidal Valdevaqueros beach also consists of medium sand, although overall somewhat coarser than at Victoria beach, ranging from 0.29 to $0.47 \mathrm{~mm}$ after the $2 \mathrm{~min}$ sieving time (Fig. 4). In all three samples, the median diameter decreases slightly with increasing sieving time, before stabilizing at values between $0.26 \mathrm{~mm}$ and $0.43 \mathrm{~mm}$ after $10 \mathrm{~min}$. The relative error of the master sample decreases
PARAMETER
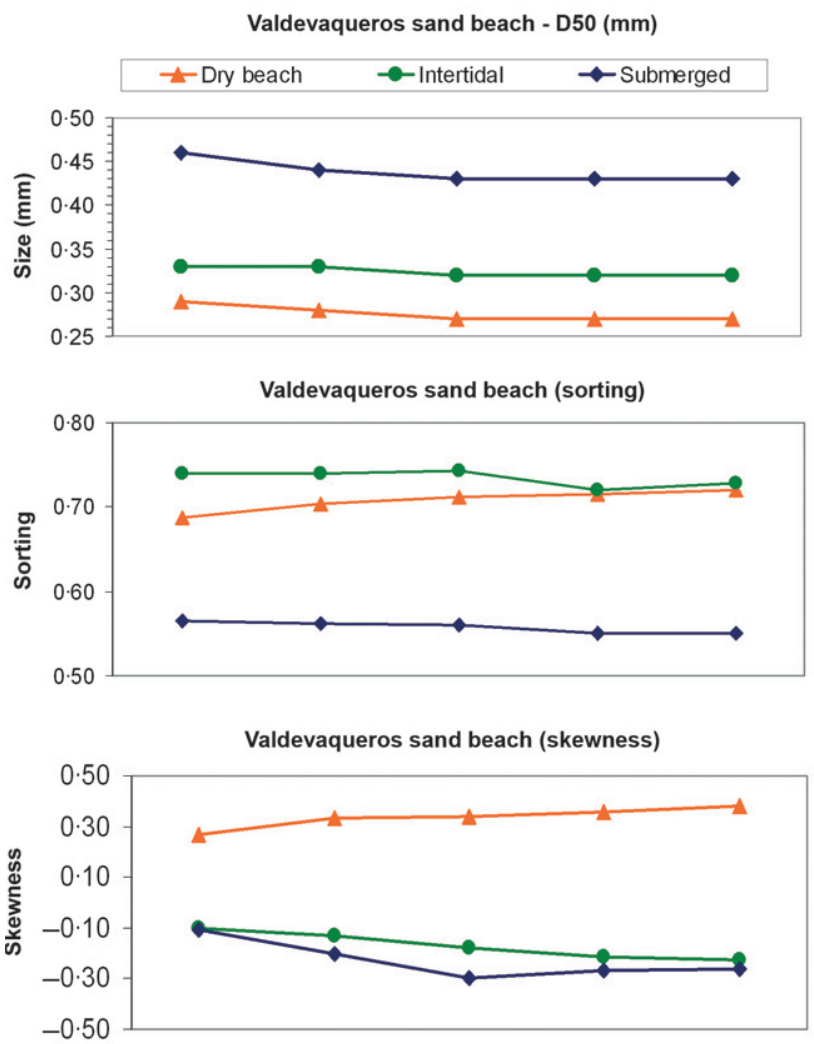

Valdevaqueros sand beach (kurtosis)

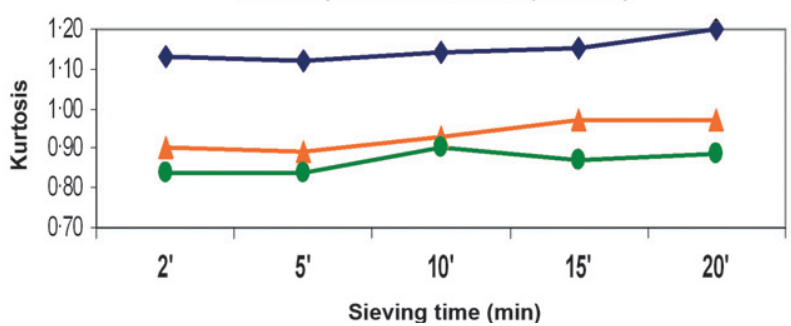

RELATIVE ERROR (\%)

Relative error (\%) of the percentage retained valdevaqueros sand beach master sample

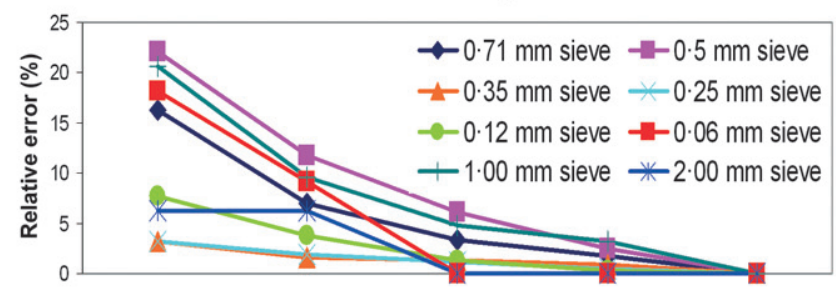

Valdevaqueros sand beach (relative error - sorting)
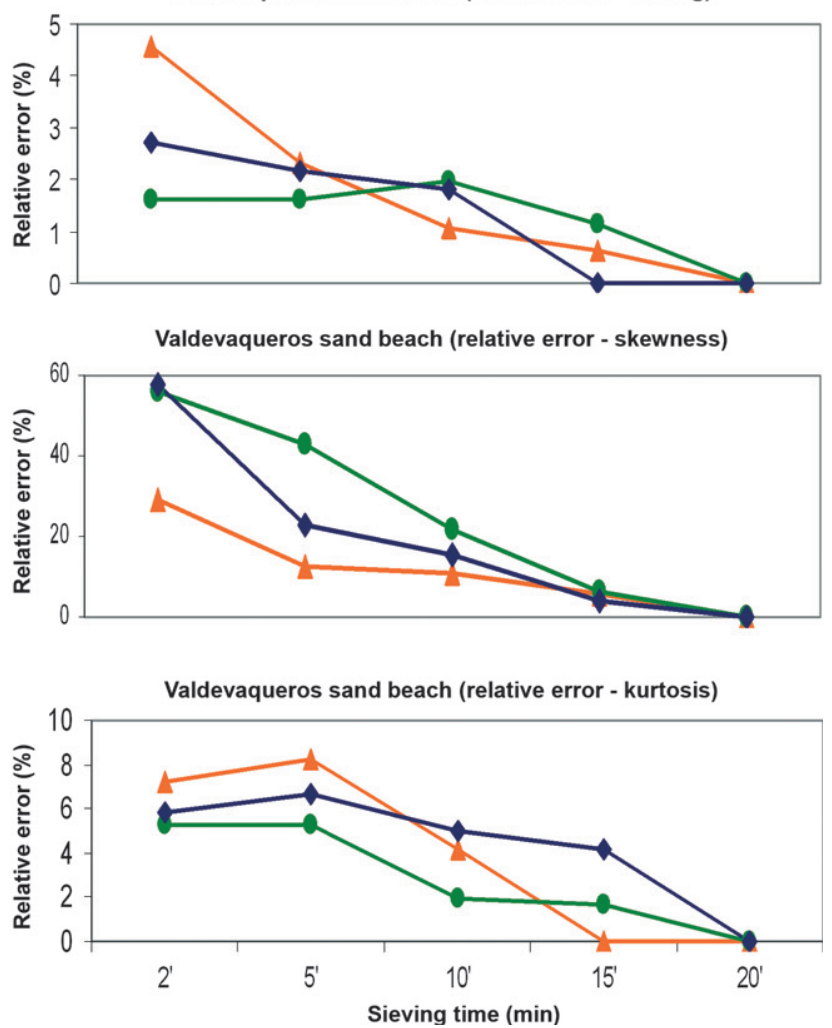

Fig. 4. Median grain size, sorting, skewness, kurtosis and relative errors as a function of sieving time for Valdevaqueros beach samples.

(C) 2013 The Authors. Journal compilation (C) 2013 International Association of Sedimentologists, Sedimentology, 60, 1484-1497 
clearly with increasing sieving time, becoming $<6 \%$ after $10 \mathrm{~min}$.

The sorting of the samples remains stable throughout the sieving time, reflecting moderately well-sorted sands. The submerged sand $\left(\sigma_{\phi}=0.55\right)$ is better sorted than the rest of the beach $\left(\sigma_{\phi}=0.69\right.$ to 0.74$)$. The relative error decreases with increasing sieving time, reaching errors $<2 \%$ after $10 \mathrm{~min}$ for all samples.

The skewness increases in all three samples, the dry beach samples getting slightly more positively skewed $\left(\alpha_{\phi}=0.25\right.$ to 0.35$)$, while the other two samples get more negatively skewed from -0.10 to $-0 \cdot 3$. The relative error is the same as in the Victoria beach sand, reaching $<8 \%$ after $15 \mathrm{~min}$.

The kurtosis essentially remains stable, except for a slightly growing tendency after $5 \mathrm{~min}$ sieving time. Valdevaqueros beach samples are platykurtic with a tendency towards a mesokurtic shape (normal peakedness with $\beta_{\phi}=0 \cdot 80$ to $0 \cdot 95$ ), with the exception of the submerged sample, which has a leptokurtic distribution $\left(\beta_{\phi}=1.10\right.$ to $\left.1 \cdot 20\right)$. In all three cases, the relative error is $<10 \%$ after $2 \mathrm{~min}$ and $<5 \%$ after $10 \mathrm{~min}$ sieving time.

\section{Influence of sieving time on the Valdevaqueros dune samples}

The grain analyses of the four sand samples collected across the highly mobile transverse dune system of Valdevaqueros classify the dune sand as consisting of medium sand, the $\mathrm{D}_{50}$-values ranging between $0.28 \mathrm{~mm}$ and $0.34 \mathrm{~mm}$ after the 2 min sieving time (Fig. 5). As at the other sites, the median diameter diminishes slightly with increasing sieving time, but stabilizes after $10 \mathrm{~min}$, with the exception of the dune foot sample which requires $15 \mathrm{~min}$ to stabilize. The relative error of the master sample decreases asymptotically with increasing sieving time, reaching $<5 \%$ after $15 \mathrm{~min}$.

Sorting decreases slightly with sieving time, except at the dune crest where it increases marginally. Overall, the dune sand is moderately well-sorted. With a sorting value of $\sigma_{\phi}=0.52$, the windward sand is better sorted than the dune foot sand $\left(\sigma_{\phi}=0.71\right)$; this explains the longer sieving time needed by the dune foot sand to reach a stable $D_{50}$-value. The relative error decreases with sieving time, reaching $0 \%$ for the windward, leeward and dune foot samples after $10 \mathrm{~min}$. The dune crest sample, by contrast, lags behind, reaching a relative error of $3 \%$ after $10 \mathrm{~min}$. All four dune samples are slightly negatively skewed and generally tend towards lesser skewness, i.e. towards more symmetrical distributions, with increasing sieving time $\left(\alpha_{\phi}=-0.30\right.$ to $\left.-0 \cdot 10\right)$. An exception is the dune foot sand, the skewness increasing from -0.21 to -0.31 after $5 \mathrm{~min}$ before stabilizing. The relative error in skewness diminishes with sieving time for all samples, reaching a highest value of $20 \%$ after $10 \mathrm{~min}$ and $<9 \%$ after $15 \mathrm{~min}$. It is worth mentioning here that the decreasing tendency is strongest for the dune foot sand, which has a relative error close to $50 \%$ after $2 \mathrm{~min}$ but reaches zero after $15 \mathrm{~min}$.

Kurtosis remains stable for the first $5 \mathrm{~min}$ and then decreases slightly with sieving time. However, although the windward, leeward and dune foot samples are all platykurtic $\left(\beta_{\phi}=0.75\right.$ to 0.85$)$, the dune crest sample is leptokurtic at first and then becomes mesokurtic (normal peakedness $\beta_{\phi}=1.00$ to 1.10 ) after $10 \mathrm{~min}$. The relative error for the kurtosis is $<10 \%$ after $2 \mathrm{~min}$ and $<5 \%$ after $10 \mathrm{~min}$ for all samples.

\section{DISCUSSION}

All of the samples analysed in this study consist of medium sand. In general, the median grain sizes diminish slightly during the first $10 \mathrm{~min}$ of sieving time and stabilize thereafter, with the exception of the Valdevaqueros dune foot sample, which becomes stable after $15 \mathrm{~min}$ due to its poorer sorting $\left(\sigma_{\phi}=0 \cdot 71\right)$ and platycurtic nature $\left(\beta_{\phi}=0.75\right)$. All other parameters (i.e. sorting, skewness and kurtosis) show only small changes with sieving time. The relative error for each parameter decreases rapidly with sieving time and stabilizes after 10 to $15 \mathrm{~min}$.

When comparing the sands of Victoria beach $\left(D_{50}=0.28\right.$ to 0.32$)$ with the sands of Valdevaqueros beach $\left(D_{50}=0.29\right.$ to 0.47$)$, the maximum relative errors after $10 \mathrm{~min}$ are $3 \%$ and $6 \%$, respectively. For the Valdevaqueros dune $\left(D_{50}=0.28\right.$ to 0.34$)$, the maximum error is $10 \%$ after $10 \mathrm{~min}$ and $5 \%$ after $15 \mathrm{~min}$. This difference suggests that the dune sands are generally less well-sorted than the beach sands. In contrast to the other localities, the kurtosis of all dune samples shows a slightly decreasing tendency towards $15 \mathrm{~min}$, tending towards very platykurtic and more poorly sorted grain-size distributions.

The main results of this study are summarized in Table 5, which shows the maximum relative 
PARAMETER
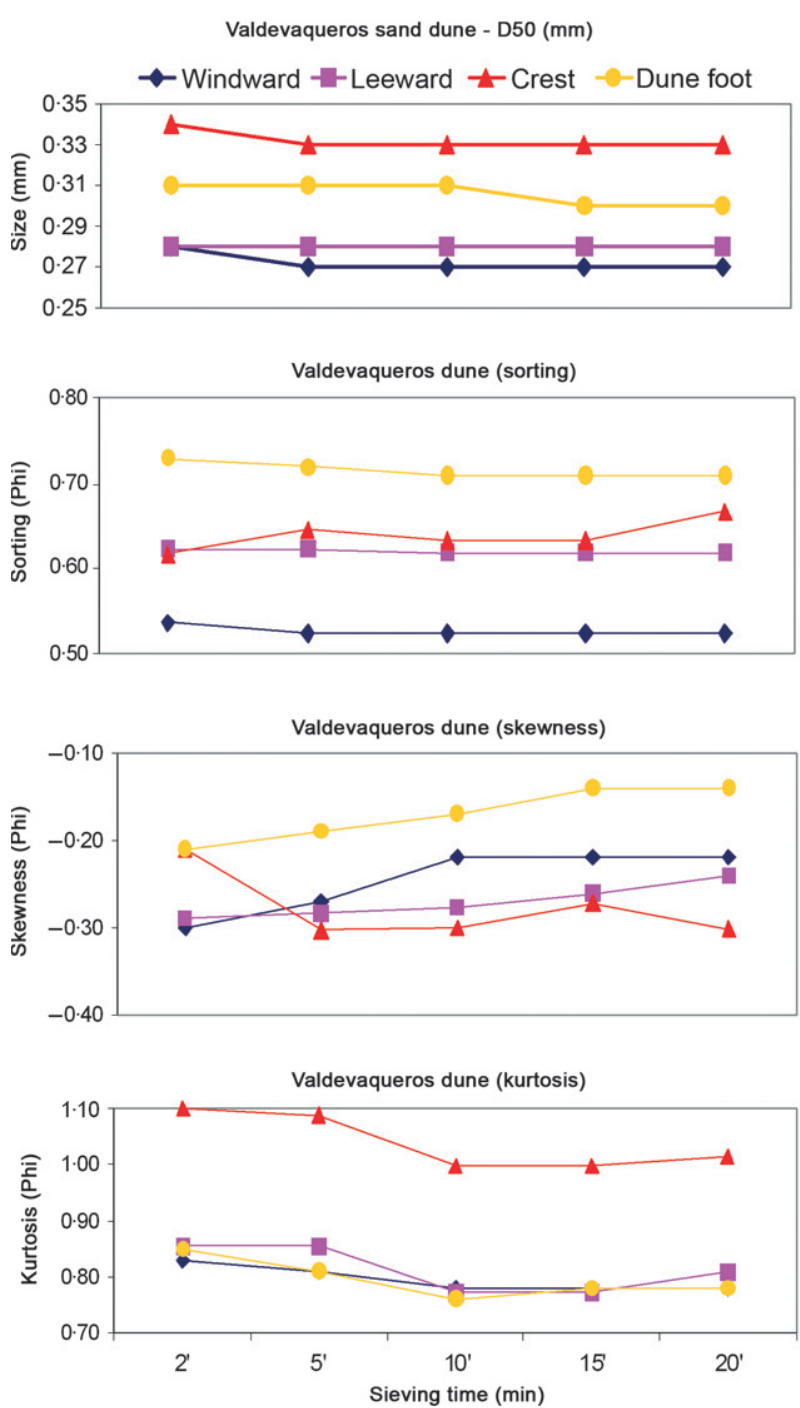

RELATIVE ERROR (\%)
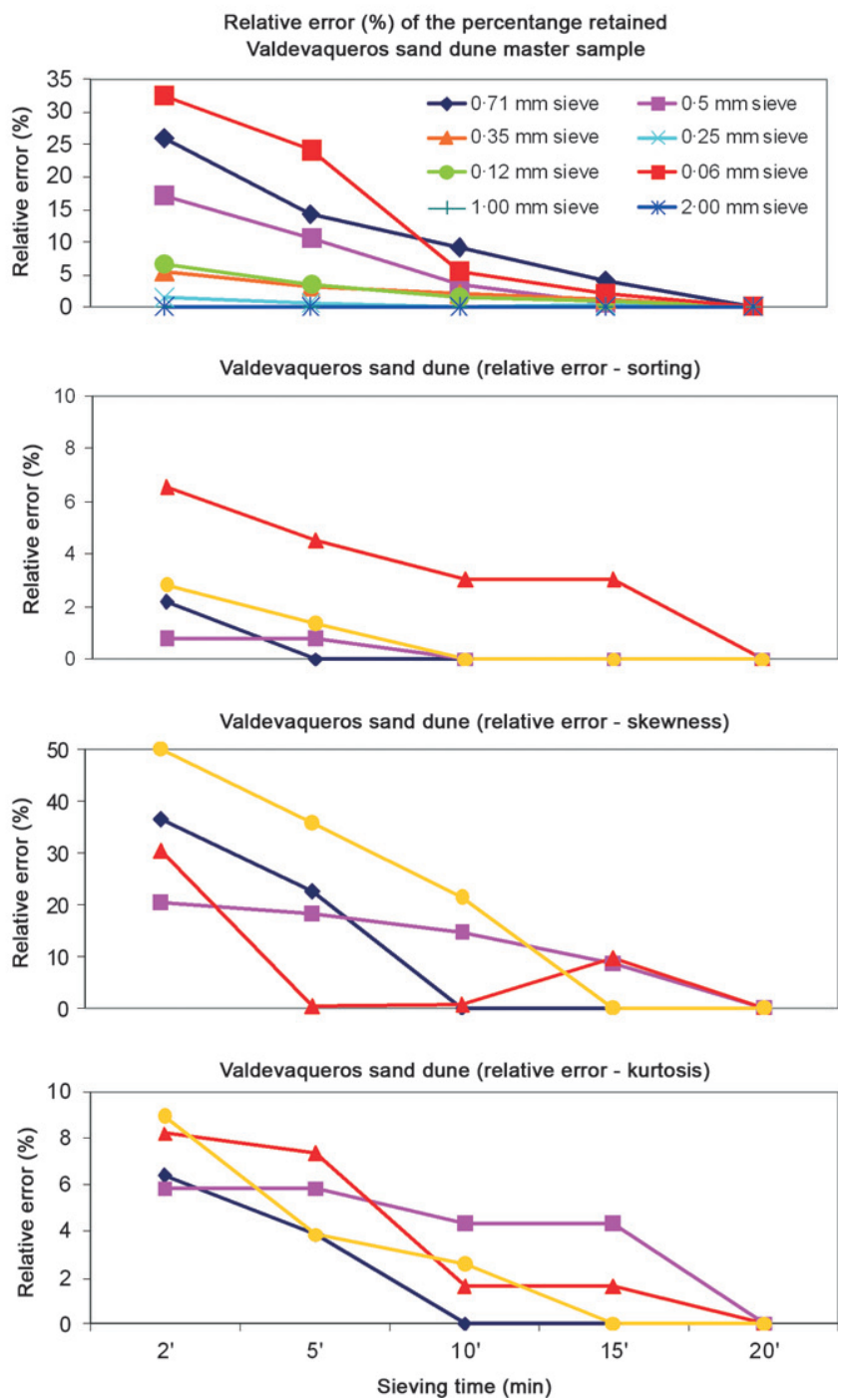

Fig. 5. Median grain size, sorting, skewness, kurtosis and relative errors as a function of sieving time for Valdevaqueros dune samples.

Table 5. Maximum relative error percentage for the studied statistical parameters related to each sand master sample for different sieving times.

\begin{tabular}{|c|c|c|c|c|c|c|c|}
\hline & \multirow[b]{2}{*}{ Sieving time (min.) } & \multicolumn{2}{|c|}{ Victoria beach } & \multicolumn{2}{|c|}{$\begin{array}{l}\text { Valdevaqueros } \\
\text { beach }\end{array}$} & \multicolumn{2}{|c|}{$\begin{array}{l}\text { Valdevaqueros } \\
\text { dune }\end{array}$} \\
\hline & & $10^{\prime}$ & $15^{\prime}$ & $10^{\prime}$ & $15^{\prime}$ & $10^{\prime}$ & $15^{\prime}$ \\
\hline \multirow{4}{*}{$\begin{array}{l}\text { Maximum relative } \\
\text { error }(\%)\end{array}$} & $\mathrm{D}_{50}$ & $3 \%$ & $2 \%$ & $6 \%$ & $3 \%$ & $10 \%$ & $4 \%$ \\
\hline & Sorting & $0 \%$ & $0 \%$ & $2 \%$ & $2 \%$ & $3 \%$ & $3 \%$ \\
\hline & Skewness & $30 \%$ & $10 \%$ & $20 \%$ & $10 \%$ & $20 \%$ & $9 \%$ \\
\hline & Kurtosis & $5 \%$ & $0 \%$ & $5 \%$ & $4 \%$ & $5 \%$ & $4 \%$ \\
\hline
\end{tabular}

error of each parameter for sieving times of 10 and $15 \mathrm{~min}$. The values demonstrate clearly that 10 min of sieving time is sufficient to obtain reliable and consistent data for the computation of textural parameters for samples from these environments. The maximum relative error is around $6 \%$, except for the skewness parameter which needs 15 min of sieving time to reach a 


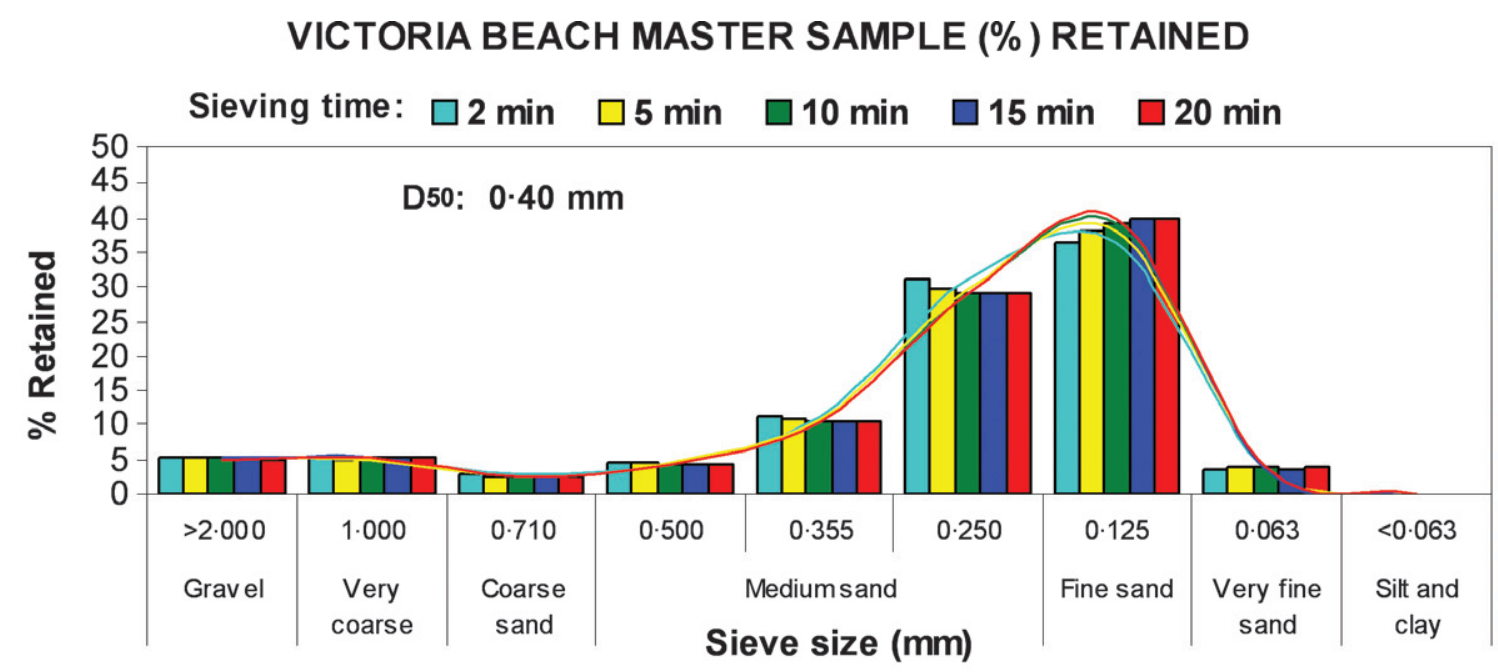

VALDEVAQUEROS BEACH MASTER SAMPLE (\%) RETAINED

Sieving time: $\square 2 \mathrm{~min} \quad \square 5 \mathrm{~min} \quad \square 10 \mathrm{~min} \square 15 \mathrm{~min} \quad \square 20 \mathrm{~min}$

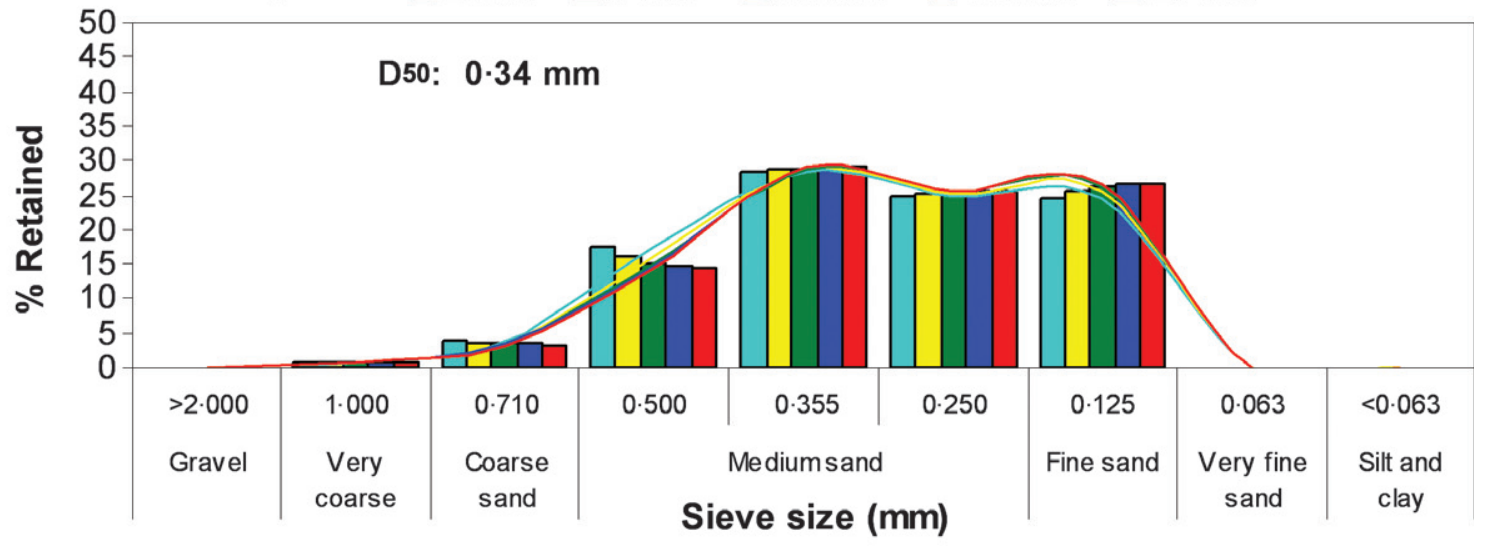

VALDEVAQUEROS DUNE MASTER SAMPLE (\%) RETAINED

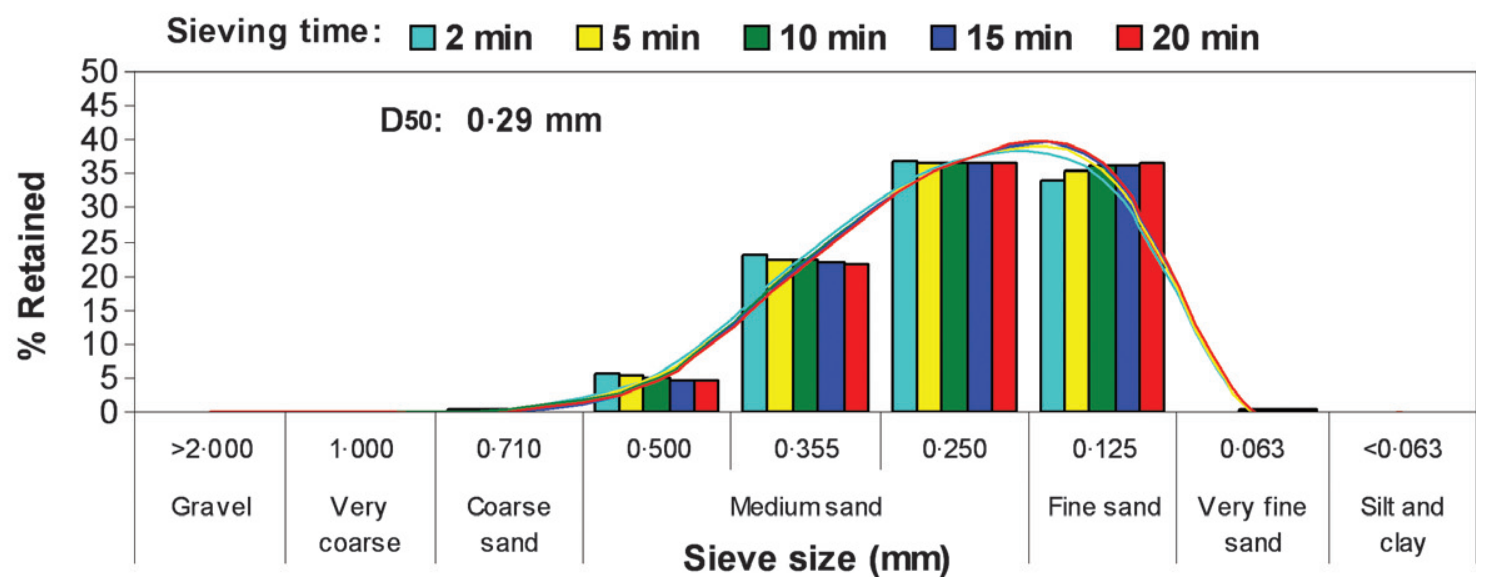

Fig. 6. Percentage retained versus sieve size fractions $(\mathrm{mm})$ for different sieving times of Victoria beach, Valdevaqueros beach and Valdevaqueros dune master samples. 
relative error around $10 \%$. For the dune samples, $15 \mathrm{~min}$ are needed to obtain maximum relative errors under $4 \%$ for all parameters except skewness (9\%), which tends towards more positive values when the sieving time is increased. This trend shows that all sand samples have a tendency towards more symmetrical distributions when sieving time increases. The differences in skewness may be due to variable contents of irregularly shaped particles in the individual samples. This fact suggests that factors such as particle shape (roundness and sphericity) and average particle size may influence the relative error in sieving and should, therefore, be the focus of future research.

The percentages of retained material in individual sieve size fractions for different sieving times are illustrated in Fig. 6. According to Syvitski (1991), increasing sieving time increases the probability for a particle to pass through a lower sieve, thereby diminishing the percentages of coarse and medium sands retained in upper sieves $(0.500$ to $0.250 \mathrm{~mm})$. This statement is confirmed by the present study, which shows that the retained percentages of the Victoria beach master sample diminish over time for coarse and medium sand sieves $(0.500$ to $0.250 \mathrm{~mm})$. For fine sand sieves $(0.125 \mathrm{~mm})$, however, this tendency reverses with more of this sand being retained with increasing sieving time, although the trend stabilizes after $10 \mathrm{~min}$. This phenomenon can be explained by enhanced sieving efficiency with increasing sieving time. However, because small amounts of this size fraction remain in the upper sieves, no clear tendency can be detected in this respect.

In the case of the Valdevaqueros beach master sample, the retained percentages diminish with increasing sieving time for coarse sand $(0.710 \mathrm{~mm}$ and $0.500 \mathrm{~mm})$. Again, this tendency reverses, but this time in the $>0.355 \mathrm{~mm}$ sieve fraction where the sand retained initially increases with sieving time before stabilizing after 10 min. This sand fraction has a bimodal size distribution and the computation of textural parameters can thus produce spurious results because it is composed of a mixture of two different grain-size populations, a phenomenon frequently observed in nature (Flemming, 2007).

In the case of the Valdevaqueros dune master sample, the percentage of sand retained over time decreases progressively for both the $0.5 \mathrm{~mm}$ and $0.355 \mathrm{~mm}$ sieves. In medium sand sieves $(0.250 \mathrm{~mm})$, sand retention becomes stable after $10 \mathrm{~min}$. In contrast to the $0.355 \mathrm{~mm}$ sieve, the fine sand sieve $(0.125 \mathrm{~mm})$ shows a similar trend to that observed in the Victoria beach sample, accumulating increasingly more sand with sieving time. The amount of sand retained by the other sieves is so small that no clear tendencies can be distinguished. The low percentage $(<5 \%)$ retained by the very coarse and very fine sand sieves for all the master samples is insufficient for a quantitative analysis.

Larger grains in the 0.710 to $0.250 \mathrm{~mm}$ sieves evidently produce a hammering effect, which allows more grains to pass through the $0.125 \mathrm{~mm}$ sieve. The same effect was observed in other experiments dealing with a marine sand sample (Syvitski, 1991) and where pieces of rubber and brass were added to the individual sieves (Batel, 1971). It can thus be concluded that sieving time is an important factor in allowing sand grains to pass through to their appropriate sieve fractions. The results of this study demonstrate that the optimal sieving times proposed for the dune and the two beach environments are associated with low relative errors for every statistical parameter derived from the grain-size analysis.

\section{CONCLUSIONS}

In this study, the influence of sieving time on the accuracy of grain-size analyses of samples from two medium-grained microtidal and mesotidal beaches and a dune has been investigated with the aim of optimizing sieving time to achieve maximum sieving efficiency in the minimum amount of time. The main conclusions can be summarized as follows:

1 The comparison of grain-size analyses on three replicate samples from each environment shows almost negligible maximum relative errors and standard deviations, thereby demonstrating that the error caused by the methodology was insignificant.

2 Sieving efficiency generally improved with sieving time. To reduce sieving time to an acceptable limit, relative errors for each parameter were calculated. On this basis, an optimal sieving time of $10 \mathrm{~min}$ for the beach samples and $15 \mathrm{~min}$ for the dune samples was determined. Longer sieving times did not substantially improve the results.

3 This study has revealed that previously suggested sieving times of between 15 and $20 \mathrm{~min}$ for all types of sand (Syvitski, 1991; USACE, 2008) can be regarded as crude guidelines only. 
4 The optimal sieving times derived at in the course of this study have both technical and economical relevance because time efficiency is achieved without sacrificing precision in the computation of textural parameters commonly used to describe grain-size distributions. It is therefore recommended that similar studies be carried out for environments other than those included in this study.

\section{ACKNOWLEDGEMENTS}

The authors would like to acknowledge all the members of the Coastal Engineering research group (RNM-912) for their contribution in the performance of this research.

\section{REFERENCES}

Anfuso, G. and Gracia, F.J. (2005) Morphodynamic characteristics and short-term evolution of a coastal sector in SW Spain: implications for coastal erosion management. J. Coast. Res., 21(6), 1139-1153.

Baquerizo, A. and Losada, M.A. (2008) Human interaction with large scale morphological evolution. An assessment of the uncertainty. Coast. Eng., 55(7-8), 569-580.

Barbanti, A. and Bothner, M.H. (1993) A procedure for partitioning bulk sediments into distinct grain-size fractions for geochemical analysis. Environ. Geol., 21, 3-13.

Batel, W. (1971) Introduction to the Technology of Grain Size Measurement. Springer-Verlag, Berlin, 214 pp.

Batman, S. and Dougherty, E.R. (1997) Size distributions for multivariate morphological granulometries: texture classification and statistical properties. Opt. Eng., 36, 1518 -1529 .

Benavente, J., Gracia, F.J., Anfuso, G. and López-Aguayo, F. (2005) Temporal assessment of sediment transport from Beach nourishments by using foraminifera as natural tracers. Coast. Eng., 52(3), 205-219.

Bernabeu, A.M., Medina, R. and Vidal, C. (2002) An equilibrium profile model for tidal environments. Sci. Mar., 66(4), 325-335.

Beuselinck, L., Govers, G., Poesen, J., Degraer, G. and Froyen, L. (1998) Grain-size analysis by laser diffractometry: comparison with the sieve-pipette method. Catena, 32, 193-208.

Blair, T.C. and McPherson, J.G. (1999) Grain-size and textural classification of coarse sedimentary particles. J. Sed. Res., 69, 6-19.

Blatt, H., Middelton, G.V. and Murray, R.C. (1980) Origin of Sedimentary Rocks, 2nd edn. Prentice-Hall, Englewood Cliffs, N.J., 766 pp.

Blott, S.J. and Pye, K. (2001) Gradistat: a grain size distribution and statistics package for the analysis of unconsolidated sediments. Earth Surf. Proc. Land., 26, 1237-1248.

Blott, S.J. and Pye, K. (2006) Particle size distribution analysis of sand-sized particles by laser diffraction: an experimental investigation of instrument sensitivity and the effects of particle shape. Sedimentology, 53(3), 671685.

Bui, E.N., Mazullo, J. and Wilding, L.P. (1990) Using quartz grain size and shape analysis to distinguish between aeolian and fluvial deposits in the Dallol Bosso of Niger (West Africa). Earth Surf. Proc. Land., 14, 157166.

Buscombe, D. and Masselink, G. (2009) Grain-size information from the statistical properties of digital images of sediment. Sedimentology, 56(2), 421-438.

Chen, Y. and Dougherty, E.R. (1994) Gray-scale morphological texture classification. Opt. Eng., 33, 2713-2722.

Dalsgaard, K. and Jensen, J.L. (1985) A methodological study of the sieving of small sand samples. In: Proceedings of the International Workshop on the Physics of Blown Sand, pp. 609-632. Mem. 8, Department of Theoretical Statistics, Institute of Mathematics, Aarhus University, Denmark.

Davies, J.L. (1964) A morphogenic approach to world shorelines. Zeitschrift für Geomorphologie, Mortensen Sonderheft8, 127-142.

Flemming, B.W. (2000) A revised textural classification of gravel-free muddy sediments on the basis of ternary diagrams. Cont. Shelf Res., 20(10-11), 1125-1137.

Flemming, B.W. (2007) The influence of grain-size analysis methods and sediment mixing on curve shapes and textural parameters: implications for sediment trend analysis. Sed. Geol., 202(3), 425-435.

Folk, R.L. (1954) The Distinction between Grain Size and Mineral Composition in Sedimentary-Rock Nomenclature. J. Geol., 62(4), 344-359.

Folk, R.L. (1974) Petrology of Sedimentary Rocks. Hemphill Publishing Company, Austin, TX.

Folk, R.L. and Ward, W.C. (1957) Brazos river bar: a study in the significance of grain size parameters. J. Sed. Petrol., 27, 3-26.

Friedman, G.M. (1979) Differences in size distributions of populations of particles among sands of various origins. Sedimentology, 26, 3-32.

Friedman, G.M. and Johnson, K.G. (1982) Exercises in Sedimentology. Wiley, New York.

Friedman, G.M. and Sanders, J.E. (1978) Principles of Sedimentology. Freeman, New York, 792 pp.

Galofré, J., Montoya, F.J. and Medina, R. (1996) Beach nourishment in Altafulla, Spain: verification of theoretical models. ICCE, 368, 4730-4743.

Gómez-Pina, G., Fages, L., Ramírez, J.L., Muñoz-Pérez, J.J. and Enríquez, J. (2006) A critical review of beach restoration projects in the northern coast of Cadiz (Spain) after thirteen years. ICCE, 30(4), 4167-4178.

Gutiérrez-Mas, J.M., Moral, J.P., Sánchez, A., Dominguez, S. and Muñoz-Perez, J.J. (2003) Multicycle sediments on the continental shelf of Cadiz (SW Spain). Estuar. Coast. Shelf Sci., 57(4), 667-677.

Krumbein, W.C. (1934a) Size frequency distributions of sediments. J. Sed. Res., 4(2), 65-77.

Krumbein, W.C. (1934b) The probable error of sampling sediments for mechanical analysis. Am. J. Sci., 227, 204 214.

Krumbein, W.C. (1939) Graphic presentation and statistical analysis of sedimentary data. In: Recent Marine Sediments (Ed. P.D. Trask), pp. 558-591. Dover, New York, 1968.

Krumbein, W.C. and Pettijohn, F.J. (1938) Manual of Sedimentary Petrography. Appleton-Century-Crofts, New York. 
Lund-Hansen, L.C. and Oehmig, R. (1992) Comparing sieve and sedimentation balance analysis of beach, lake and eolian sediments using log-hyperbolic parameters. Mar. Geol., 107(1-2), 139-142.

Matheron, G. (1975) Random Sets and Integral Geometry. Wiley, New York, 261 pp.

Medina, R., Losada, M.A., Losada, I.J. and Vidal, C. (1994) Temporal and spatial relationship between sediment grain size and beach profile. Mar. Geol., 118(3-4), 195-206.

Mizutani, S. (1963) A theoretical and experimental consideration on the accuracy of sieving análisis. J. Earth Sci., 11(1), 1-27.

Muñoz-Perez, J.J. and Medina, R. (2000) Profile changes due to a Fortnightly Tidal Cycle. 27th International Conference on Coastal Engineering (ASCE), Sydney. pp. 3062-3075.

Muñoz-Perez, J.J., Navarro, M., Román-Sierra, J., Tejedor, B., Rodriguez, I. and Gomez-Pina, G. (2009) Long-term evolution of a transgressive migrating dune using reconstruction of the EOF method. Geomorphology, 112, 167-177.

Navarro, M., Muñoz-Perez, J.J., Román-Sierra, J., Tsoar, H., Rodriguez, I. and Gomez-Pina, G. (2011) Assessment of highly active dune mobility in the medium, short and very short term. Geomorphology, 129(1-2), 14-28.

Pye, K. (1994) Properties of sediment particles. In: Sediment Transport and Depositional Processes, (Ed. K. Pye), pp. 124. Blackwell, Oxford.

Román-Sierra, J., Navarro, M., Muñoz-Perez, J.J. and Gomez-Pina, G. (2011) Turbidity and other effects resulting from Trafalgar sandbank dredging and Palmar beach nourishment. J. Waterw. Port Coast. Ocean Eng., 137(6), 332-343.

Rubin, D.M. (2004) A simple autocorrelation algorithm for determining grain size from digital images of sediment. J. Sed. Res., 74, 160-165.

Sand, F. and Dougherty, E.R. (1998) Asymptotic granulometric mixing theorem: morphological estimation of sizing parameters and mixture proportions. Pattern Recogn., 31(1), 53-61.

Shepard, F. P. (1954) Nomenclature based on sand-silt-clay ratios. J. Sed. Petrol., 24, 151-154.

Spanish Port System (2011) http://w3.puertos.es/en/ sistema_portuario/index.html

Syvitski, J.P.M. (1991) Principles, Methods, and Application of Particle Size Analysis. Cambridge University Press, New York, $368 \mathrm{pp}$.

Tanner, W.F. (1969) The particle size scale. J. Sed. Petrol., 39, 802-812.

USACE (2008) Coastal sediment properties. US Army Corps of Engineers. Coastal Engineering Manual - Part III. EM 1110-2-1100.

Wentworth, C.K. (1922) A scale of grade and class terms for clastic sediments. J. Geol., 30, 377-392.

Manuscript received 9 October 2011; revision accepted 6 February 2013 